\title{
On the Manifestation of the Pearl Embroidery Art in the Ready-made Clothes Design
}

\author{
Deng Qionghua \\ Jiangxi Institute of Fashion Technology,Department of Dress Design and Engineering \\ Jiangxi Institute of Fashion Technology, JF \\ Nanchang, Jiangxi \\ 348908682@qq.com
}

Keywords: The Pearl Embroidery; Ready-made Clothes; Clothes Style; Market

\begin{abstract}
With the fast development of the clothing industry, the designers are pursuing the creation of the design, the breakthrough of the design and the unlimited imagination of the design, which were all embodied in the style of the clothes, the color of the clothes, the material of the clothes, the art and the detail of the clothes. The detail design is very important in the design, which was thought to be the space of developing creation and obtaining inspiration. However, the style design had achieved the summit, that is why many designers are pursuing the new inspiration and the breakthrough, and the clothes decoration has become of them. The pearl embroidery art in the decoration had been used in many aspects, which was used broadly in the high-level customtailored. With the development of the trends, the pearl embroidery art was used in the ready-made clothes design. The pearl embroidery decoration had become a factor of the clothes design with the effect of the style and the art. The pearl embroidery has many forms to express its importance.
\end{abstract}

\section{The First Part, the Research Background of the Pearl Embroidery Art}

With the development of more than 5000 years, our ancestors have left people the brilliant culture and the traditional arts, which had form the regular and overall industry line. Under the modern industry production method, the pure decoration all by hand had disappeared gradually, because they cost much time and hardly meet the needs of the society, which also led to the loss of the brilliant traditional arts. Nowadays, people are pursuing the perfect combination of the fashion of the clothes, the trend of the aesthetic and the pearl embroidery art. Under this situation, the designers must master and understand the different manifestation forms of the pearl embroidery, considering the characters of the clothes to improve the unique decoration art method, to broad the application field, to manifest the characters of the richness and the diversity. The pattern and other manifestations in the embroidery contained the national culture and the wisdom of the ancestors.

\section{The Second Part, the Concept and the Characters of the Embroidery}

The embroidery art is a handicraft techniques. Some materials, such us the diamond, the crystal and the artificial pearl were strung through the line and fitted into the material, all of them were made by the adept hand craft. The clothes with the decoration looked like elegant and unique with full of cubic beauty feeling. The simple and easy embroidery was made through the pearl line one by one, which was born after the embroidery and just had a short history. Due to the difference and of the art and the pearl, it contained all kinds of culture. Today, it can be used in the high-level custom-tailored and the general ready-made clothes. What is more, it had great development space and charm in the stage space performance, just as follows:

It Looks Bright. The characters of the pearl embroidery lie in the unique and the richness of the material. It is a decoration of our clothes through the shell, the bugle, the pearl and the artificial pearl which all shined under the sun. It could inspire our eyesight and made the clothes look like elegant. 
The Refraction Character of the Material. The concave and the convex of the shell, the section of the artificial pearl and the Acryl Diamond has manifested the refraction effects, which made the pearl embroidery excel other decorations.

The Special Cubic Decoration Effect. The characters of the pearl embroidery lie in the use of all kinds of pearls. The pearl could be understood into the dot, and the dot is the base of the model. The line was formed by the dot, and the space was formed by the line, and the space formed the cubic. After the use of different forms such us density, repeat, gradual color, the cubic decoration characters

\section{The Third Part,the Manifestation in the Ready-made Clothes Design of the Pearl Embroidery.}

The ready-made clothe must meet the needs of the society through the massive production. Of course, the cost must be considered firstly in the production. That means to pursuit the profit greatly. In order to obtain the profit greatly, the clothes must be accepted by the market and the customers. As you know, the ready-made clothes do not aim the single, but the group. Therefore, the simple, the comfort, the cheap and the popularity must concentrated the general clothes, which is different from the high-level Custom-tailored. However, the needs of the people are increasing day after day. It is hoped that what they are wearing not only comfortable but also unique, which had become the direction of the modern ready-mad clothes. But how to produce the decoration of the clothes through the massive machine production and decrease the cost of the production is what I will concern.

The Requirement of Massive Production. The clothes design is very commercial, and you must have competition ability to adapt to the market. But how to obtain the competition ability? You must know about the needs of the market, the characters of adapting to the industry production of readymade clothes. How to make the women clothes look like more attractive; how to combine the industry production with the traditional decoration craft and the fashion factor; which had become the direction and the premise of the ready-made clothes market.

The decoration craft such as embroidery and pearl embroidery which was used into the market ready-made design had a shortcoming: costing too much time and money. Therefore, how to decrease the cost and meet the needs of massive production has become the first problem needing to be solved. As you know, the computer embroidery machine also called the special embroidery machine was born. It can finish many crafts which were finished by hand before it was introduced. The computer embroidery machine could finish color embroidery, sew jewelry, quitting, ribbon embroidery, disk flower embroidery and tuft stitch. The use of the computer embroidery machine greatly save the labor, decrease the cost, which made it become possible for the use of decoration craft in the ready-made production. However, it has the space to improve. For example, the computer embroidery machine only can work under the hard material, and the soft material easily to wrinkle, and it is not delicate with the embroidery by hand.

In these years, the embroidery technology in China had developed quickly, and it had formed the base in Zhejiang. As you know, due to its many varieties, massive production and more functions, which had become very important to the Zhejiang's status. There is no doubt that the computer embroidery machine endowed new lives to the clothes and made the ready-made clothes market more colorful. (Fig. 1)

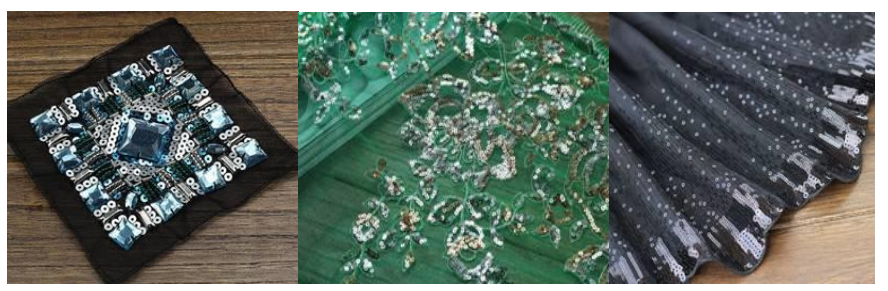

Figure 1. The Use of Patterns in Couture.

The Situation Survey of the Pearl Embroidery's Supply and Demand in China The Purpose of the Market Survey 
Aiming the women market to master the craft needs of the women consumers towards the clothes decoration. Through the survey, researches can obtain their consumer idea, popular extent, brand consciousness. After that, the author analyzed the information and master the market trend through the analyzing the collection. Only by this way, the needs of the pearl craft decoration in the clothes market further can be known.

Why do the Survey?

Master the Real Needs of the Consumers

The author could design the suitable product just after he had an overall understanding towards the market, and the market survey is the best way to know that. Some enterprises which did not know about the market completely provide the production and the trend for the consumers just according to one-side judgment. They did not know the real color, style, decoration craft, function and match of the production. Through the form of the survey, people could directly know the consumer's reflection and needs, improving the extent of needing.

Provide the Base for the Market Decision

Through the survey carried by the department of planning, it could provide the promise for the production supply in next quarter. As you know, there are much risks judging the market only by experience. People must avoid the blindness and the subject. The successful enterprise usually made their decision towards the clothes market through the market survey and the experienced design chief's judgment.

Master the Opponent's Information

The market survey is an important way to collect the information of the opponent. Know yourself and know your enemy, people will get victory. In the market survey, people need find the similar style, brand and price with our production. Through the survey, people should get the characters of the opponent's production and consuming strategy. After that, it provide the object base for beating the opponent. As you know, if one brand has much space in the market, it will become the competition brand for the opponent. Only doing the delicate to the market, people could occupy the market in the first time.

The Method of the Market Survey

In order to achieve the aim of the market survey, people must adopt a certain method to analyze the information. The usual market survey contains the field survey and the bibliography survey. The former contains the special survey and the market brand survey, which was used to obtain the first information; the later was used to obtain the second-hand information. Of course, the best way is to combine the two surveys. Next, I will analyzed the special survey, the market brand observation survey and bibliography survey.

The Special Survey

In this survey, the problem in the survey questionnaire was designed by the special people, and the problem were answered by the special people. Considering the real situation, it could be classified into interview survey and writing survey. In this survey, researchers distributed 500 women who aged from 18 to 50 to understand the needs of the pearl embroidery.

The survey was sent to the object through the micro channel and QQ. The survey was designed as follows. (Fig. 2)

According to the conclusion of the survey, the age of from 25 to 30 occupies $35 \%$, from 18 to 24 occupies $20 \%$, they go shopping more than 2 times every month, containing shopping through the Internet, costing at least 100 yuan. Their requirement towards the clothes must have its characters. What is more, they paid much attention to the decoration craft, such as the pearl embroidery, printing flower and the comprehensive manifestation. 


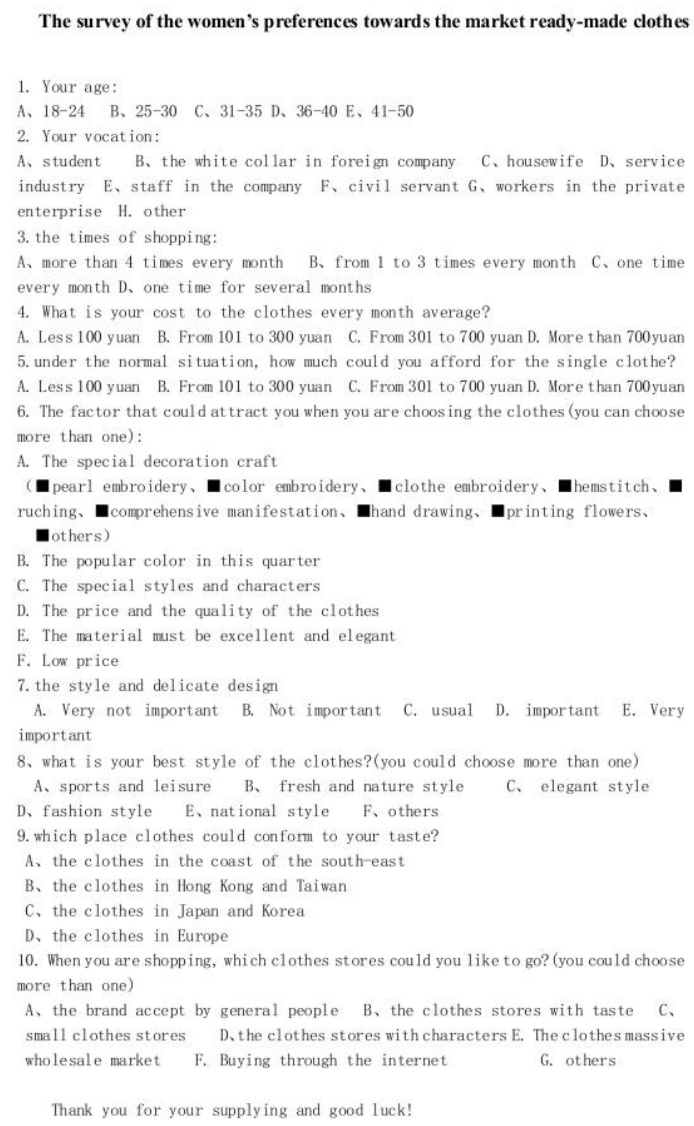

Figure 2. Survey on Market Clothing Female Preferences

The Market Brand Observation Survey

In july, 2014, I made many surveys in Nanchang Mall.such as Wanda square, Department Store, Rainbow Store, Parkson Shopping Center. The clothes in these malls had one obvious character: match with the pearl embroidery and have the excellent and delicate craft. (Fig. 3) besides, I had made some surveys in the street and master the preferences of the women in Nanchang. (Fig. 4) Through the photo, it can be known the application of the decoration in the market and the choice of the consumers.
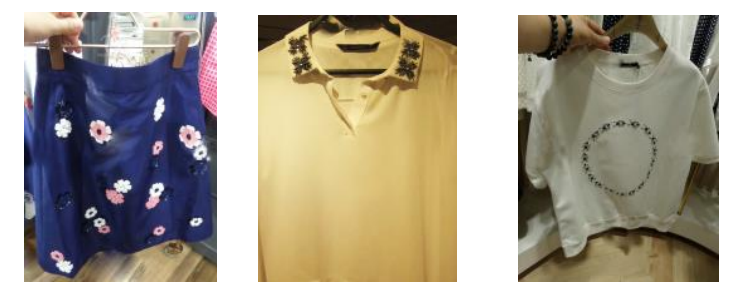

(1) Ochirly

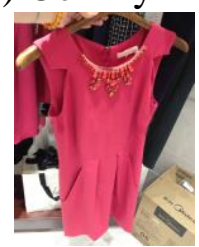

(2) ZARA

(3) Etam

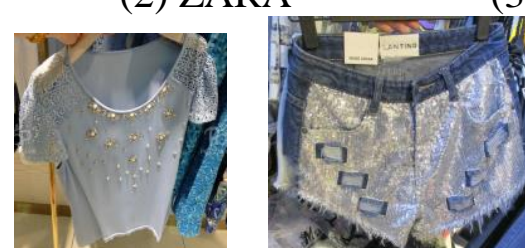

(4) Marisfrolg

(5) LANCY FROM

(6) LANTING

Figure 3. The Real Photo of the Application to the Pearl Embroidery in Nanchang Market

(1) the Ochirly brand (2) the ZARA brand (3) the Etam brand

(4) the Marisfrolg brand (5) the LANCY FROM brand (6) the LANTING Brand 


\section{The Bibliography}

People can get much information about the clothes through the internet. Through this way, people could get know the development situation of the pearl embroidery material market. (Fig. 5)
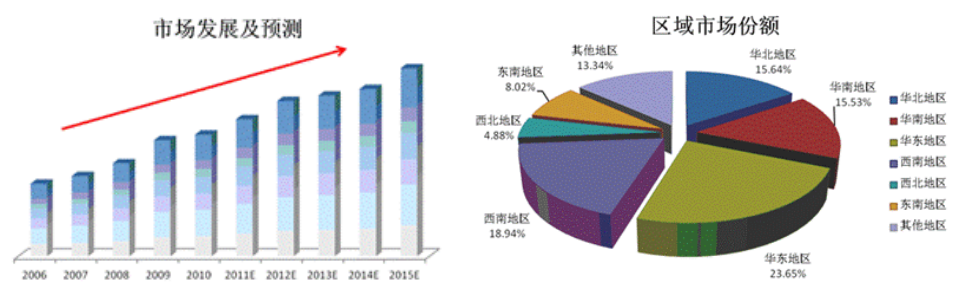

(1) Predicts the Development of Global Bead Piece Embroidery Fabric Market 2012-2015

(2) the Analysis of the 2013 Bead Piece Embroidery Fabric Regional Market

Figure 5. The Network to Collect Data Information

The Results of the Survey

Through the survey, could get know the top place of the clothe brand, such as H\&M, ZARA, ONLY, VERO MODA, CC\&DD, Ochirly, Meters Bonwe, LANCY FROM, PEACE BIRDS, Marisfrolg, Etam. These clothes were matched through the pearl embroidery in the summer of 2014. From that, it could forecast that the pearl embroidery will occupy a great market in 2015 and go gradually.

The Application of the Pearl Embroidery in Different Style Ready-Made Clothes.

In order to meet the needs of industry production, when people are designing the market readymade clothes, people make the clothes look more perfect through the match of the pearl embroidery, and people must consider some principles: according the clothes style to choose the suitable pearl embroidery and patterns. Different pearl embroidery material had different style trend, people should show the inspiration of the designer through the combination of different pearl embroidery manifestation.

The Application of the Pearl Embroidery to the Leisure Style Clothes

The leisure style was accept by most people. It could embody the transition of the clothes with other style clothes, such as sports leisure, garden leisure, fashion leisure, business leisure. The characters of the leisure clothes are comfortable, simple, and casual. It has no special requirements of the age and the somatotype towards the consumers. Giordano, Meters Bonwe, Yishion and Semir have occupied many shares in the market.

The $\mathrm{H}$ type was often used to the external contour of the leisure clothes, because it was loose and nature and it has no many trends to the model factors. The pattern, as a factor of the model, was used in the dot often; the seams line often was used in the line model; the space model which was cut could manifest the hierarchy feeling. In the use of the material, people emphasize the comfort. Therefore, the nature fiber cotton and the fiber were often used according to the trend factors.

In the delicate design, the collar was changing always, the hooded collar was often used. The pocket was made into patch pocket and welt pocket. The trademark and the pattern often were often highlighted to set off the sight center. The pearl embroidery decoration craft was often used in Tshirt. It was used with the combination of the pattern, especially the pearl embroidery method. Some had the pearl in part, other had in whole, which made the clothes look like elegant and beautiful. The material of the pearl has many types to choose, such as the grain pearl, the paillette, Acrylic imitation diamond. Of course, the popular color in the year often was adapted to match the clothes. (Fig. 6)

The Application of the Pearl Embroidery in the Fashion Style 


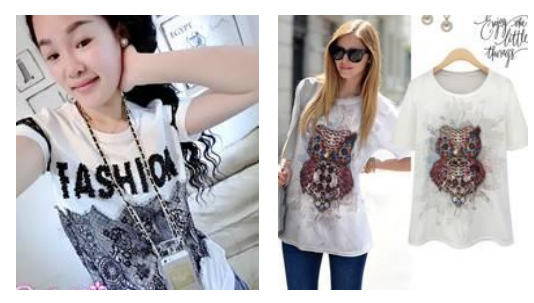

Figure 6. Embroidered in Leisure Style Clothing Performance

Fashion style paid attention to the weird and emphasized the creation, the revolt and the obstinate. It opposed the tradition and did by themselves to differ from others. The model is not symmetrical and the sleeve is exaggerated. The pocket appeared to be the tank pocket and the cubic pocket. The material is smooth through the coating and the leather. Such as the jeans, which were torn. The jeans had the strips and exaggerated patterns or words. As you know, the rivet, the patch and the edge are all the representative factors in the fashion style.

The fashion style contains the hippie style, the punk style, the dadaism style, the pop style, the poor socialism, the Euro style and the futurism style. The punk style in the fashion style was often decorated by the use of the rivet which was a pearl embroidery decoration craft. The metal rivet and the black material were the main characters of the punk style. (Fig. 7).
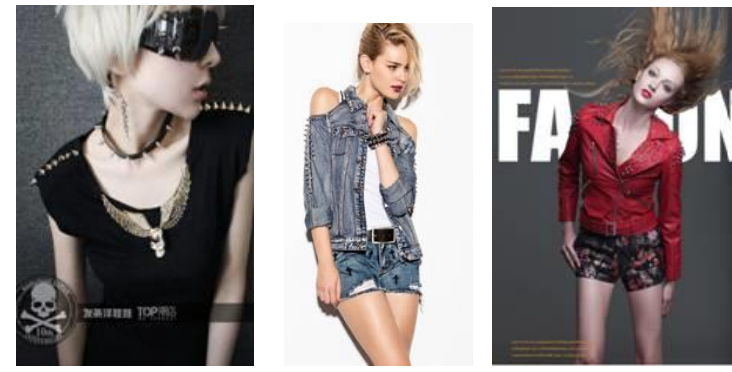

Figure 7. Embroidered in the Avant-Garde Style of Clothing Performance

The Application of the Pearl Embroidery in the Elegance Style

The elegance style emphasized the women character style. It is noble and delicate, elegant and steady, fashion and beauty. The style emphasized the details, it had high quality towards the clothes. The model emphasized the X type and the A type. In the choice of the model factors, the dot, the line and the surface were not limited too much. In the pearl embroidery design, the concrete pattern and line were used to make the women characters prominent. The soft gray color and the connotation color with the women emphasized the noble and elegant style. Therefore, the color of the pearl embroidery usually had the similar color with the material. The line model emphasized the waist and the breast of the women. The curve was used to cut the princess line and the breast line. The material were all smooth and excellent. The clothes were matched with the lace, the silk and the satins. (Fig. 8)
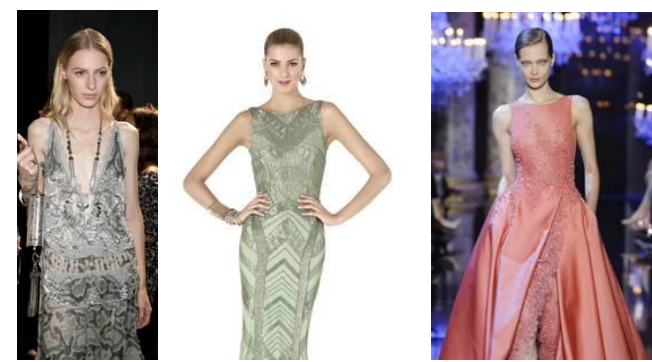

Figure 8. Embroidered in the Performance of Elegant Style in Clothes

The Application of the Pearl Embroidery in the National Style 
The national style contains the special clothes of all the world. Many designers occupied the market shares by the writing of the national inspiration. For example, John Galliano. Who created the series of Egypt, the series of China and Japan; the series of Arab by the rise of the Hermes, which were designed by the national factors.

The national style had many styles and had their characters. The rough of the west jeans, the enthusiasm of the Gypsy and the fresh of the Korea. However, most traditional clothes emphasized the hand craft, such as flowers embroidery, ralph lauren, dish button and glass embroidery. Our country has many minority nations, and the folk tradition is rich, which were the quintessence of Chinese culture. It could be adopted by the Chinese folk. Many pearl embroideries were used in the design. For example, the artificial pearl, the paillette and the skeleton. They have strong colors and contrast greatly. (Fig. 9).
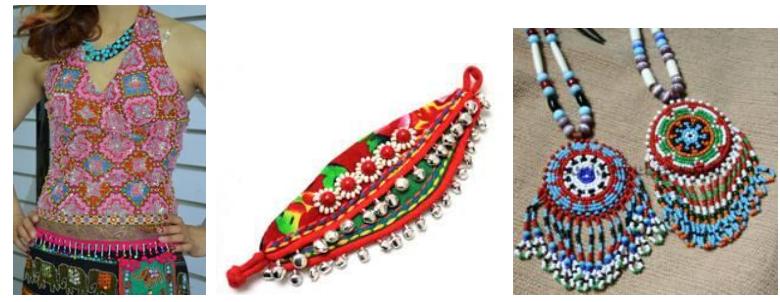

Figure 9. Embroidered in the National Style of Clothing Performance

The Application of the Pearl Embroidery in the Romantic Style

The romantic style is full of youthful spirit, and it is suitable to the young women. Especially the miniskirt. The style is not limited. A type, $\mathrm{O}$ type and $\mathrm{X}$ type were often designed by the designer. The dot could manifest the surface through the material pattern and the craft pattern. The color is bright, such as pink, pure and anthocyanidin. What is more, it emphasized the details, such as hubble-hubble, many lotus leaf level, small round collar and lace.

The romantic style is sweet, the wet pearls, the soft scale and the grain pearl were often used in the pearl embroidery decoration. The artificial pearl collar was very popular among the consumers in recent years. (Fig. 10).
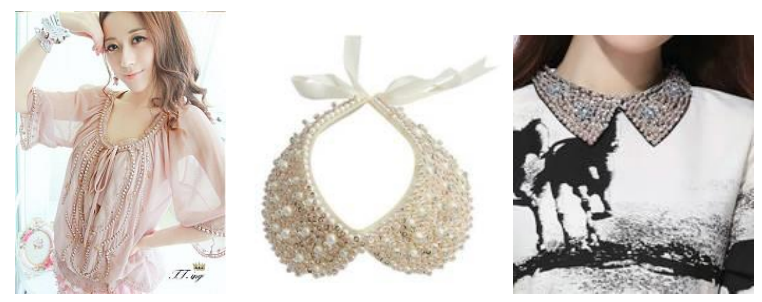

Figure 10. Embroidered in the Romantic Style of Clothing Performance

\section{Conclusion and Future}

The thesis analyzed the research background of the pearl embroidery, the concept of the pearl embroidery and the application of the pearl embroidery in the different ready-made clothes style. The results show that the computer embroidery machine brought high efficiency with the development of the industry production comparing with the traditional craft surface and cubic embroidery technology. Besides, it decreased the cost and met the needs of the consumers. Of course, the research provide a base for the future research of the pearl embroidery. It emphasized the concept of China.

The process of the science accelerated the birth of the machine, and the birth of the machine decreased the cost of the pearl embroidery and increased the application of the pearl embroidery in the clothes. At present, the pearl embroidery developed quickly, and Chaozhou city had become the 
important base of the pearl embroidery production, which was the distributing center of the pearl embroidery after the reform and opening. Of course, it promoted the development of Chaozhou. With the overall development of the earth, many foreign orders about the pearl embroidery processing moved into China from other countries. The people in Chaozhou grasped the chance, combined with the local craft technology to complete the ready-made clothes and form industry chain to develop into the massive industry.

\section{References}

[1] Li Chuan, Shi Lin. On the Craft of the Haute Couture [J]. Nantong Textile Vocational Technology College. 2003, 01:39-41

[2] Xu Linjian, Zhu Hanyu, Yin Yanmei. On the manifestation form of the embroidery flowers to the Haute Couture[j]. Art and Design (theory), 2011, 06: 228-230.

[3] Yin Yanmei. Zhu Hanyu,Xu Linjian. The Application of the Clothes Craft to the Modern knitting clothes[j]. The Journal of Zhejiang Science University.2010, 01: 84-88+144.

[4] Wang Lei. The enlightenment of the Voss to the Modern Clothes Industry[j]. Shangdong Textile Economic. 2009, 02: 86-88.

[5] Haugh Gardner. Learn the pearl embroidery from Zero [M]. China Textile Press.Oct, 2013.

[6] Liu Xiaogang Cui Yumei, the Basic Clothes Design [M]. Donghua University press. March, 2003.

[7] Hua Mei. The History of China Clothes [M]. The first version of October, 2007.

[8] Martin R H, Koda H. Haute couture [M]. Metropolitan Museum of Art, 1995.

[9] Chen Bin, the Style of Fashion Design [M]. The first version of september, 2007

[10] Liu Yuanfeng, the Clothes Design [M]. Beijing, Higher Education Press. 2005 